\title{
Mandibular Osteolytic Lesion Associated with Exuberant Hyaline Ring Granuloma Reaction
}

\author{
Luciana Yamamoto Almeida ${ }^{a}$ Paulo Alceu Kiemle Trindade ${ }^{b}$ \\ Alexander Tadeu Sverzut $^{b}$ Cassio Edvard Sverzut ${ }^{b} \quad$ Alexandre Elias Trivellato $^{b}$ \\ Christiano Oliveira-Santos ${ }^{c}$ Jorge Esquiche León ${ }^{c}$ \\ ${ }^{a}$ Oral Pathology, Department of Oral Diagnosis, Dentistry School of Piracicaba, University of Campinas \\ (FOP/UNICAMP), Piracicaba, ${ }^{b}$ Department of Oral and Maxillofacial Surgery and Periodontology, University of \\ São Paulo, School of Dentistry of Ribeirão Preto (FORP/USP), and ' Oral Pathology, Department of Stomatology, \\ Public Oral Health, and Forensic Dentistry, University of São Paulo, School of Dentistry of Ribeirão Preto \\ (FORP/USP), Ribeirão Preto, Brazil
}

\section{Key Words}

Odontogenic cystic lesion · Hyaline ring granuloma · Pulse granuloma $\cdot$ Mandible

\section{Abstract}

Objective: To report an unusual case of oral hyaline ring granuloma (HRG) that caused an extensive osteolytic lesion. Clinical Presentation and Intervention: A 22-year-old female was referred to our hospital with a large expansile cystic lesion in the left mandibular ramus associated with a clinically visible, partially erupted third molar. A diagnosis of paradental cyst was made. After marsupialization of the lesion, histopathological analysis of the surgical specimen showed an unusual exuberant HRG reaction supported by scarce fibrous stroma. Conclusion: This was a case of exuberant HRG reaction that caused extensive bone destruction.

\section{KARGER}

\section{Introduction}

Hyaline ring granuloma (HRG) is a localized granulomatous inflammatory lesion considered to be a foreign body reaction to vegetable particles [1]. It occurs most frequently in the oral cavity associated with impacted lower third molar or in postextractive alveolar sockets [1]. However, HRG has also been reported in the lung, intestine, skin, gallbladder and uterine tube [2]. Microscopically, HRGs are characterized by hyaline rings associated with multinucleated giant cells [1-4]. Oral HRGs have been found in association with inflammatory fibrous hyperplasia [1], periapical granulomas [3], and odontogenic cysts $[5,6]$. The purpose of this case was to report an exceptional case of exuberant HRG reaction that developed in the wall of a mandibular odontogenic cyst.

\section{Case Report}

A 22-year-old female patient was referred to our hospital for treatment because she complained about pain and swelling in her left cheek and presented with a clinically visible, partially erupted left inferior third molar with purulent discharge from its gingival

Luciana Yamamoto Almeid

Oral Pathology, Department of Oral Diagnosis, Dentistry School of Piracicaba University of Campinas (FOP/UNICAMP), Av. Limeira, n. 901

Piracicaba, SP CEP 13414-903 (Brazil)

E-Mail al.yamamoto@ hotmail.com 
Fig. 1. Cropped panoramic radiographs showing the affected mandible at different times. a Initial panoramic radiograph. b 9 months after tooth removal and marsupialization of the lesion. c 2 years after initial treatment. d 4 months after surgical enucleation of the lesion.

Fig. 2. a The microscopic analysis exhibited a cystic lesion of inflammatory origin. $\times 10$. b After 2 years of follow-up, the cystic lesion associated with convoluted hyalinized rings and foreign body-type multinucleated giant cells. $\times 10$. Inset Cellular details are shown. c At low magnification, numerous hyalinized rings and vegetable matter supported by fibrous stroma. $\times 5$. d Vegetable particle closely associated with foreign body-type multinucleated giant cells. $\times 20$. e Dark organic material and granulomatous foreign body response. $\times 10$. $f$ High-power view showing convoluted hyalinized rings containing calcified basophilic granules. $\times 40$. a-f $\mathrm{H} \& \mathrm{E}$.
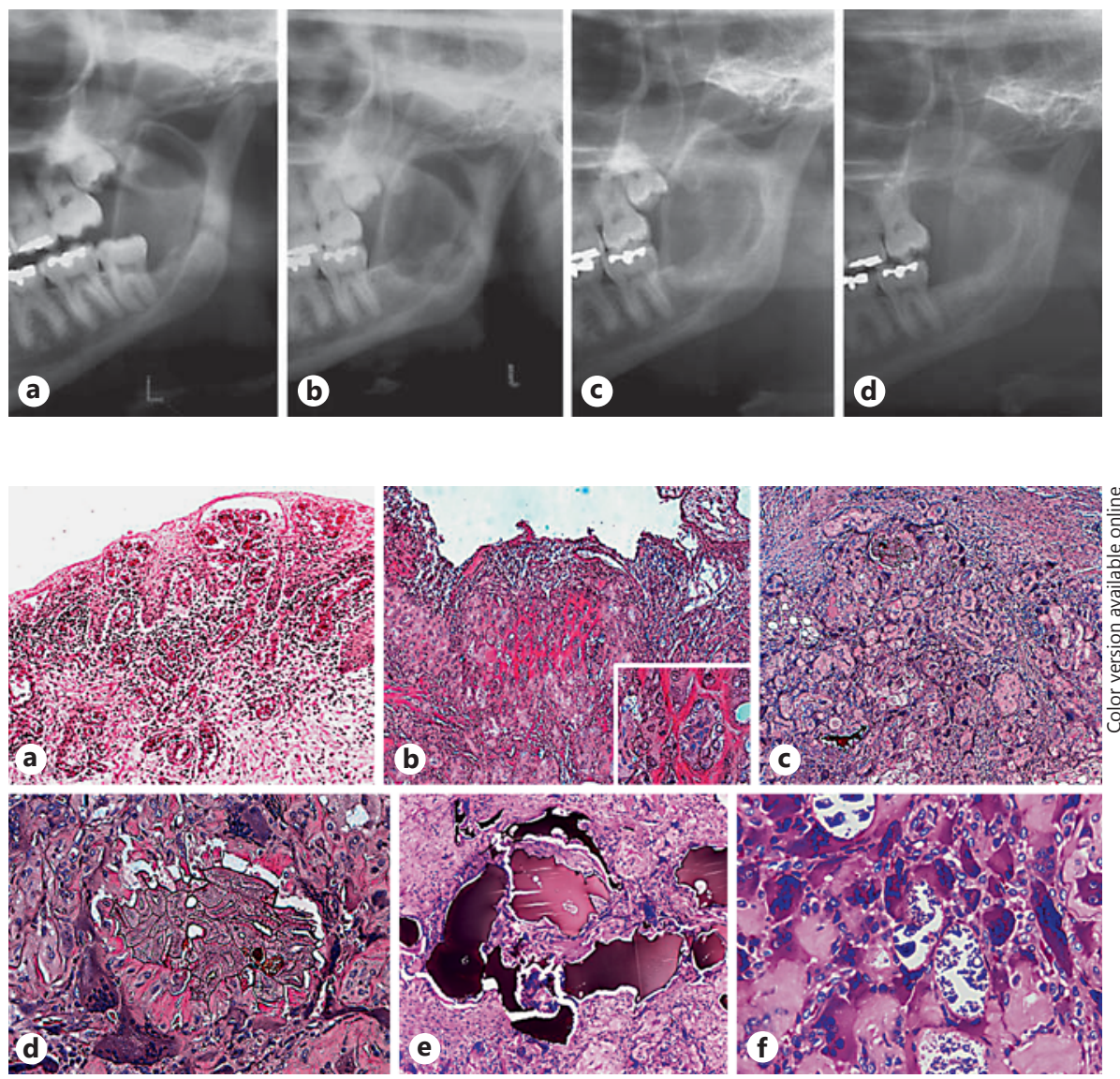

sulcus. On the panoramic radiograph, an extensive cystic-appearing lesion was visualized (fig. 1). After 7 days of oral antibiotic therapy and further evidence of a fluid-containing lesion, the tooth was surgically removed and the lesion marsupialized. The clinicopathological correlation led to the diagnosis of a paradental cyst (fig. 2a). The patient discontinued her treatment and returned 2 years later with pain and without the device for draining the marsupialized cyst. The cyst was marsupialized again, and microscopically revealed an association with focal HRG reaction (fig. 2b). The lesion was fully enucleated, and this was followed by curettage. The histopathological analysis of the entire tissue blocks showed an exuberant HRG reaction (75\% of the surgical specimen) supported by fibrous stroma (fig. 2c-f). Cyst-lining epithelial cells were not observed. On follow-up after 4 months, the panoramic radiograph showed new bone formation.

\section{Discussion}

We report herein an exceptional case of exuberant HRG reaction that developed in the wall of a mandibular odontogenic cyst. To our knowledge, similar to our case, there is only one published case showing an association of $\mathrm{HRG}$ reaction with a large radiolucent lesion in the mandible [7]; however, different from our findings, HRG reaction was observed only in the initial levels of the entire tissue block.

The paradental cyst is an inflammatory cyst that occurs most often on the buccal or distal aspect of partly erupted mandibular molars, commonly associated with a history of pericoronitis $[8,9]$. A large osteolytic lesion involving the mandibular ramus is extremely unusual for paradental cysts; thus, we believe that the exuberant HRG reaction is involved in the pathogenesis of the current lesion.

In a review of 173 cases of oral HRG, Philipsen and Reichart [10] observed that more than two thirds of the lesions occurred in the posterior region of the mandible. Most patients presented pain, swelling, discharge or a chronic sinus tract. HRGs were found as small structures, uncommonly being a significant component in the cyst wall [7]. In relation to HRG pathogenesis [10], the current case supports the exogenous theory. In fact, we have observed two distinct vegetable matters, hollow matrices 
and dark organic material. The surgical procedures indicated that therapeutic substances in the surgical area were not used. The hollow matrices contained fibrovascular tissue cores admixed with multinucleated giant cells, whereas the dark organic material induced a granulomatous foreign body response.

\section{Conclusions}

This was a case of exuberant HRG reaction, which was initially associated with a paradental cyst, and showed extensive destruction of large bone. After surgical treatment, clear signs of healing were observed.

\section{References}

$>1$ Gueiros LA, Santos Silva AR, Romañach MJ, et al: Distinctive aspects of oral hyaline ring granulomas. Oral Surg Oral Med Oral Pathol Oral Radiol Endod 2008;106:e35-e39.

$>2$ Zhai J, Maluf HM: Peridiverticular colonic hyaline rings (pulse granulomas): report of two cases associated with perforated diverticula. Ann Diagn Pathol 2004;8:375-379.

3 Talacko AA, Radden BG: Oral pulse granuloma: clinical and histopathological features. A review of 62 cases. Int J Oral Maxillofac Surg 1988;17:343-346.
4 Manjunatha BS, Kumar GS, Raghunath V: Histochemical and polarization microscopic study of two cases of vegetable/pulse granuloma. Indian J Dent Res 2008;19:74-77.

5 Pola JG, de la Cruz A, Bustillo F, et al: Pulse granuloma in the wall of an inflammatory radicular cyst. Otolaryngol Head Neck Surg 2003;129:441-442.

6 Marcussen LN, Peters E, Carmel D, et al: Legume associated residual cyst. J Oral Pathol Med 1993;22:141-144.
7 Ide F, Kusama K, Saito I, et al: Pulse granuloma in the wall of a dentigerous cyst. J Oral Maxillofac Surg 1982;40:659-662.

$>8$ Chen SY, Fantasia JE, Miller AS: Hyaline bodies in the connective tissue wall of odontogenic cysts. J Oral Pathol 1981;10:147-157.

9 Ali MA: Biopsied jaw lesions in Kuwait: a sixyear retrospective analysis. Med Princ Pract 2011;20:550-555.

10 Philipsen HP, Reichart PA: Pulse or hyaline ring granuloma. Review of the literature on etiopathogenesis of oral and extraoral lesions. Clin Oral Investig 2010;14:121-128. 